archives

of thermodynamics

Vol. 35(2014), No. 2, 37-49

DOI: $10.2478 /$ aoter-2014-0012

\title{
Analysis of temperature distribution in a pipe with inner mineral deposit
}

\author{
MAGDA JOACHIMIAK ${ }^{1}$ \\ MICHAE CIAEKOWSKI \\ JAROSŁAW BARTOSZEWICZ
}

Poznan University of Technology, Chair of Thermal Engineering, Piotrowo 3, 60-965 Poznań, Poland

\begin{abstract}
The paper presents the results of calculations related to determination of temperature distributions in a steel pipe of a heat exchanger taking into account inner mineral deposits. Calculations have been carried out for silicate-based scale being characterized by a low heat transfer coefficient. Deposits of the lowest values of heat conduction coefficient are particularly impactful on the strength of thermally loaded elements. In the analysis the location of the thermocouple and the imperfection of its installation were taken into account. The paper presents the influence of determination accuracy of the heat flux on the pipe external wall on temperature distribution. The influence of the heat flux disturbance value on the thickness of deposit has also been analyzed.
\end{abstract}

Keywords: Mineral deposit; Inverse problem

\section{Nomenclature}

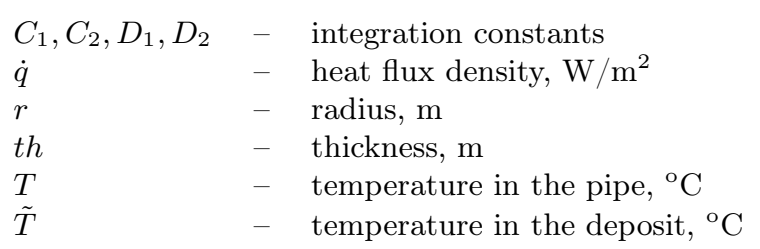

\footnotetext{
${ }^{1}$ Corresponding Author. E-mail: magda.joachimiak@put.poznan.pl
} 


\section{Greek symbols}

$\alpha \quad-$ heat transfer coefficient, $\mathrm{W} /\left(\mathrm{m}^{2} \mathrm{~K}\right)$

$\delta \quad-$ distance, $\mathrm{m}$

$\Delta-$ accuracy

$\lambda \quad-$ heat conduction coefficient, $\mathrm{W} / \mathrm{m} \mathrm{K}$

\section{Subscripts}

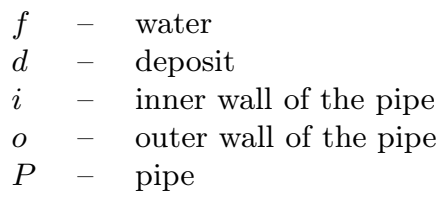

\section{Superscripts}

* - location of the thermocouple

\section{Introduction}

The aim of this study is to determine temperature distributions inside the diaphragm of a heat exchanger and in a deposit, which depend on the thickness of the deposit in the heat exchanger pipes. Experience of heat exchangers users indicates the need to predict the thickness of the boiler scale being responsible for the structure damage [10]. Water-originated boiler scale is deposited on walls of heat exchangers. Depositing scale causes a local increase in temperature gradient and, as a consequence, a development of thermal stresses. The value of additional thermal stresses depends on the heat transfer coefficient of the scale, i.e., the chemical composition of deposits. Calcium carbonate-, calcium sulfate-, and calcium silicate-based scales form an insulation layer inside pipes that obstructs the heat transfer, which leads to a growth in temperature of pipes and an increase in thermal loads [4]. This is the reason for malfunctioning of a variety of elements of heat exchangers. In order to prevent the elements from operation under the risk of damage it is necessary to monitor the depositing boiler scale and the distribution of temperature in the elements particularly exposed to overheating [5]. Diagnosing the thickness of deposits is often difficult because it is impossible to measure the temperature on the pipe outer wall that may be in contact with flame or exhaust gases. The work of the heat exchangers was analyzed using the method of the inverse problem [8]. Complexity of heat transfer results in a great measurement uncertainty. An alternative could be the measurement of temperature inside the diaphragm and searching for the value of temperature on the outer surface of the pipe by solving 
the inverse problem. The inverse method allows calculating the thickness of the scale. Calculations related to determination of the heat flux have been described in papers [3,9]. This method allows determining the temperature distribution in the pipe and in the scale. While carrying out the calculations, the influence of thermocouple location in the steel diaphragm, the installation error and the accuracy of heat flux determination on the pipe outer wall on the sensitivity of obtained temperature distributions [2] was taken into consideration.

\section{Calculation model}

The investigation was divided into two stages. The first stage focused on searching for the temperature distribution in the diaphragm material and in the deposit by solving the inverse heat conduction problem. The second stage focused on determining the influence of the sensitivity of thermocouple location, installation error and the accuracy of heat flux determination on the accuracy of the obtained solution. Figure 1 presents geometric scheme of the case under consideration. The cylindrical diaphragm of the inner radius $r_{i}$ and the outer radius $r_{o}$ is covered on the inner side with a boiler scale of a varied thickness of the radius $r_{d}$. The thermocouple is located on the radius $r^{*}$.

Due to the axial symmetry of thermal field in the pipe and in the scale, for the stationary case this field is described by the equation

$$
\frac{d^{2} T}{d r^{2}}+\frac{1}{r} \frac{d T}{d r}=0
$$

whose general integral takes the following forms:

- in the pipe

$$
T=C_{1} \ln r+C_{2} \text { for } r_{i} \leq r \leq r_{o},
$$

- in the scale

$$
\tilde{T}=D_{1} \ln r+D_{2} \text { for } r_{d} \leq r \leq r_{i} .
$$

Integration constants in the general solutions (2) and (3) were determined from the conditions:

- temperature at the measuring point $r=r^{*}$ under the surface of the pipe outer wall equals to

$$
T\left(r=r^{*}\right)=T^{*} \text { hence } T^{*}=C_{1} \ln r^{*}+C_{2},
$$




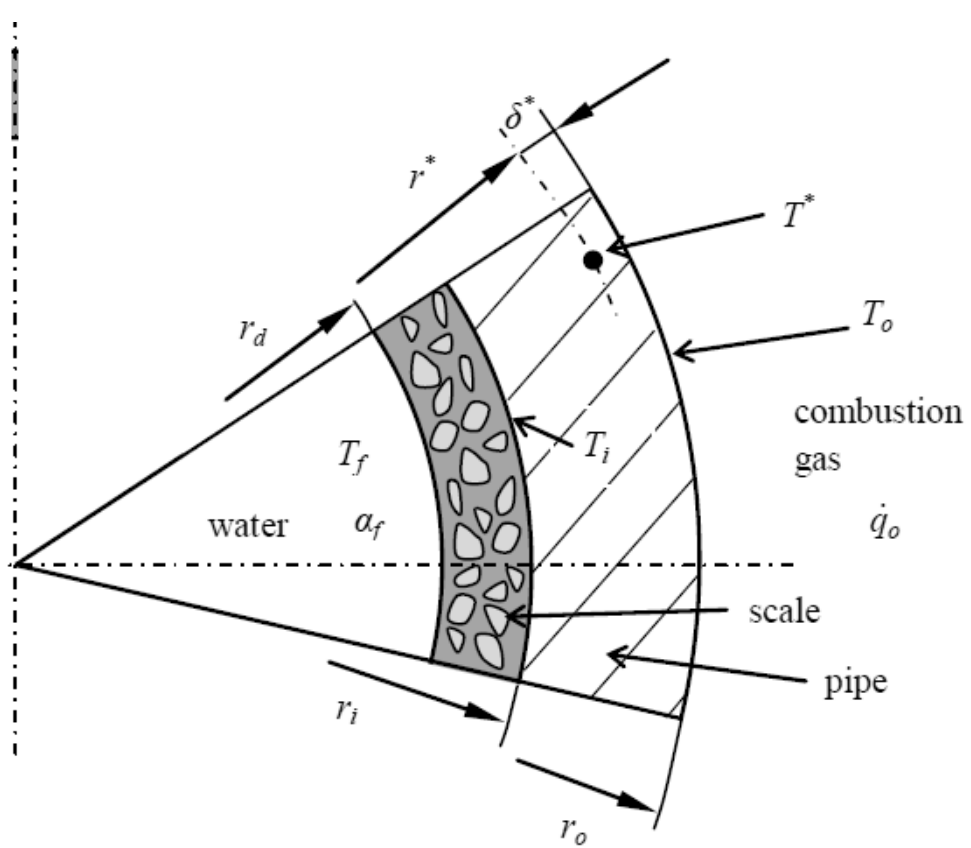

Figure 1: Cross section scheme of a pipe with boiler scale.

- heat flux density on the outer wall of the pipe

$$
-\left.\lambda_{P} \frac{\partial T}{\partial r}\right|_{r=r_{o}}=\dot{q}_{o}
$$

- temperature on the outer wall of the scale being equal to the temperature of the pipe inner wall

$T\left(r=r_{i}\right)=\tilde{T}\left(r=r_{i}\right)=T_{i}$ hence $T_{i}=D_{1} \ln r_{i}+D_{2}=C_{1} \ln r_{i}+C_{2} ;$,

- heat flux density on the inner wall of the pipe

$$
\dot{q}_{i}=-\left.\lambda_{P} \frac{\partial T}{\partial r}\right|_{r=r_{i}}=\left.\lambda_{d} \frac{\partial \tilde{T}}{\partial r}\right|_{r=r_{i}} .
$$

Taking the conditions (4)-(7) into consideration, integration constants are 
equal to:

$$
\begin{array}{r}
C_{1}=\frac{\dot{q}_{o} r_{o}}{\lambda_{P}}, \quad C_{2}=T^{*}-\frac{\dot{q}_{o} r_{o}}{\lambda_{P}} \ln r^{*}, C_{1}=\frac{\dot{q}_{o} r_{o}}{\lambda_{d}}, \\
D_{2}=T^{*}+\dot{q}_{o} r_{o}\left(\frac{\ln \left(\frac{r_{i}}{r^{*}}\right)}{\lambda_{P}}-\frac{\ln r_{i}}{\lambda_{d}}\right),
\end{array}
$$

which allows determining the temperature distribution in the pipe and in the scale. The temperature distribution in the pipe is described by the function

$$
T(r)=\frac{\dot{q} r_{o}}{\lambda_{P}} \ln (r)+T^{*}-\frac{\dot{q} r_{o}}{\lambda_{P}} \ln r^{*} \text { for } r_{i} \leq r \leq r_{o},
$$

and in the boiler scale by the function

$$
T(r)=\frac{\dot{q} r_{o}}{\lambda_{P}} \ln (r)+T^{*} \dot{q}_{o} r_{o}\left(\frac{\ln \left(\frac{r_{i}}{r^{*}}\right)}{\lambda_{P}}-\frac{\ln r_{i}}{\lambda_{d}}\right) \text { for } r_{d} \leq r \leq r_{i} .
$$

The deposit thickness $t h_{d}=r_{i}-r_{d}$ has been determined based on the condition

$$
\left.\dot{q}_{d}\right|_{r=r_{d}}=-\left.\lambda_{d} \frac{\partial \tilde{T}}{\partial r}\right|_{r=r_{d}}=\alpha_{f}\left[\tilde{T}\left(r=r_{d}\right)-T_{f}\right],
$$

where the value of heat transfer coefficient $\alpha_{f}$ and fluid temperature $T_{f}$ are known. Having inserted relations (10) to (11) the following nonlinear equation against the unknown radius $r_{d}$ of the deposit is obtained

$$
\dot{q}_{o} \frac{r_{o}}{r_{d}}=\alpha_{f}\left[T^{*}+\dot{q}_{o} r_{o}\left(\frac{\ln \frac{r_{i}}{r^{*}}}{\lambda_{P}}+\frac{\ln \frac{r_{d}}{r_{i}}}{\lambda_{d}}\right)-T_{f}\right] .
$$

The unknown value of radius $r_{d}$ has been determined using the Newton iterative method [6].

The second stage of the research analyzed the sensitivity of the solution to the function of temperature distribution in the pipe $T\left(T^{*}, r^{*}, \dot{q}_{o}\right)$ and $\tilde{T}\left(T^{*}, r^{*}, \dot{q}_{o}\right)$ in the scale on disturbances resulting from deviations of the thermocouple location (the localization error), the inaccuracy in the temperature measurement on the radius $r^{*}$ as well as the influence of the inaccuracy in determination of the heat flux density transferred on the outer surface temperature. Errors in determining the temperature distribution in 
the pipe $\Delta T\left(T^{*}, r^{*}, \dot{q}_{o}\right)$ and $\Delta \tilde{T}\left(T^{*}, r^{*}, \dot{q}_{o}\right)$ in the scale could be estimated using a total differential of these functions. Approximating them locally through a linear function we obtain values that are the measures of the function sensitivity to disturbances of arguments. Hence, in order to determine the sensitivity of the solution of temperature distribution in the pipe and in the boiler scale, determination of the derivatives is needed:

$$
\begin{array}{ll}
\frac{\partial T}{\partial T^{*}}=\frac{\partial \tilde{T}}{\partial T^{*}}=1, & \frac{\partial T}{\partial r^{*}}=-\frac{\dot{q}_{o} r_{o}}{\lambda_{P}} \frac{1}{r^{*}}, \quad \frac{\partial T}{\partial \dot{q}_{o}}=\frac{r_{o}}{\lambda_{P}} \ln \left(\frac{r}{r^{*}}\right), \\
\frac{\partial \tilde{T}}{\partial r^{*}}=-\frac{\dot{q}_{o} r_{o}}{\lambda_{P}} \frac{1}{r^{*}}, & \frac{\partial \tilde{T}}{\partial \dot{q}_{o}}=\frac{r_{o}}{\lambda_{d}} \ln r+r_{o}\left(\frac{\ln \left(\frac{r_{i}}{r^{*}}\right)}{\lambda_{P}}-\frac{\ln r_{i}}{\lambda_{d}}\right) .
\end{array}
$$

Accuracy in determination of the temperature distribution depends on the partial derivatives of functions $T$ and $\tilde{T}$ against $T^{*}, r^{*}$ and $\dot{q}_{o}$ as well as on the accuracy of the temperature $\Delta T^{*}$ determination, thermocouple $\Delta r^{*}$ location and the accuracy of the heat flux determination on the outer wall $\Delta \dot{q}_{o}[1]$. Hence,

$$
|\Delta T(r)| \leq\left|\frac{\partial T}{\partial T^{*}}\right|\left|\Delta T^{*}\right|+\left|\frac{\partial T}{\partial r^{*}}\right|\left|\Delta r^{*}\right|+\left|\frac{\partial T}{\partial \dot{q}_{o}}\right|\left|\Delta \dot{q}_{o}\right|,
$$

and

$$
|\Delta \tilde{T}(r)| \leq\left|\frac{\partial \tilde{T}}{\partial T^{*}}\right|\left|\Delta T^{*}\right|+\left|\frac{\partial T}{\partial r^{*}}\right|\left|\Delta r^{*}\right|+\left|\frac{\partial \tilde{T}}{\partial \dot{q}_{o}}\right|\left|\Delta \dot{q}_{o}\right| .
$$

Therefore, when replacing values (13) in Eqs. 14) and (15) we obtain

$$
|\Delta T(r)| \leq 1\left|\Delta T^{*}\right|+\left|\frac{\dot{q} r_{o}}{\lambda_{P}} \frac{1}{r^{*}}\right|\left|\Delta r^{*}\right|+\left|\frac{r_{o}}{\lambda_{P}} \ln \left(\frac{r}{r^{*}}\right)\right|\left|\Delta \dot{q}_{o}\right|,
$$

and

$$
|\Delta \tilde{T}(r)| \leq 1\left|\Delta T^{*}\right|+\left|\frac{\dot{q} r_{o}}{\lambda_{P}} \frac{1}{r^{*}}\right|\left|\Delta r^{*}\right|+\left|\frac{r_{o}}{\lambda_{d}} \ln r+r_{o}\left(\frac{\ln \left(\frac{r_{i}}{r^{*}}\right)}{\lambda_{P}}-\frac{\ln r_{i}}{\lambda_{d}}\right)\right|\left|\Delta \dot{q}_{o}\right| .
$$

Accuracy values of functions of temperature distribution in the diaphragm (16) and in the deposit (17) have been limited in advance by the values of errors $\Delta T^{*}, \Delta r^{*}$, and $\Delta \dot{q}_{o}$, taking derivatives (13) into consideration. 


\section{Assumptions for the calculations}

In order to determine the scale thickness a boundary (maximum) temperature level $T^{*}$ at point $r^{*}$ corresponding to the temperature on the surface of $580{ }^{\circ} \mathrm{C}$ should be determined. Based on the inverse method [7] the temperature on the outer wall of the pipe was determined depending on the thickness and type of the deposited boiler scale (Fig. 2a). For the discussed pipe geometry and the assumed boiler steel, the maximum temperature value at the measuring point was $579^{\circ} \mathrm{C}$ (Fig. 2b).

a)
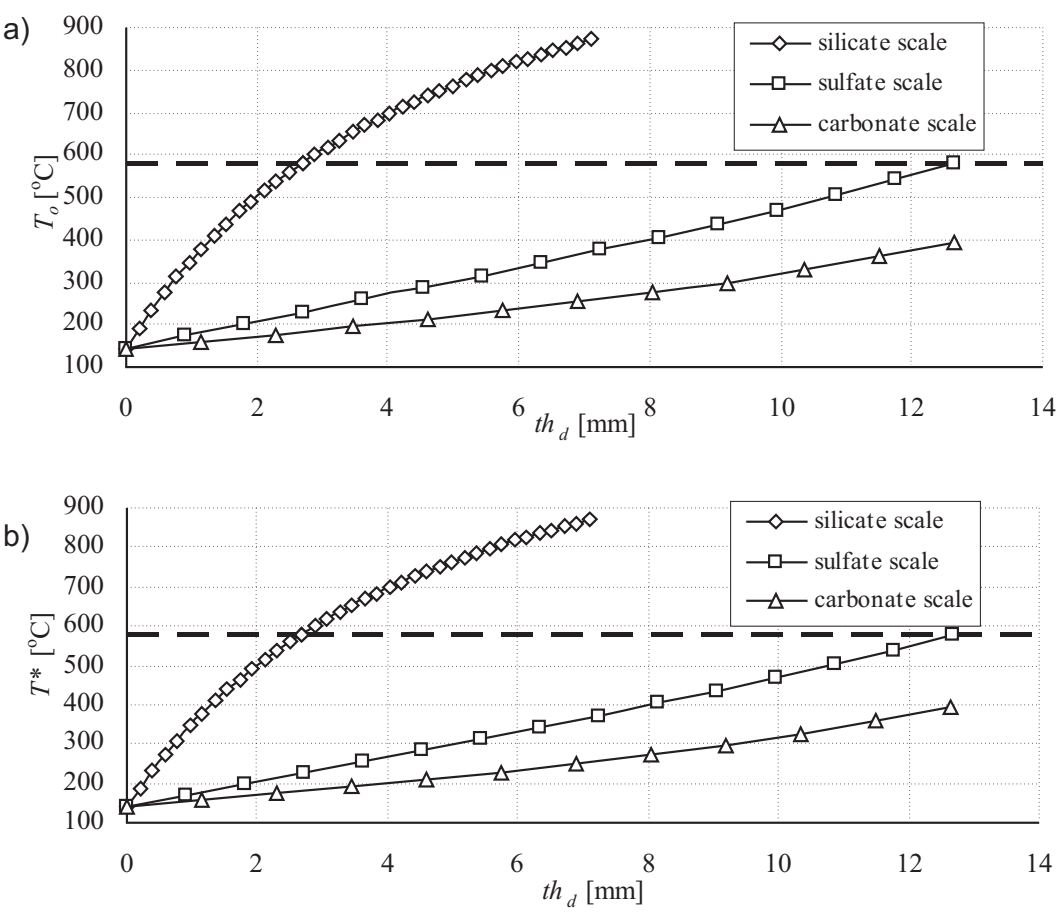

Figure 2: Change of temperature $T_{o}$ and $T^{*}$ as a function of boiler scale thickness and its type; maximum temperature on the pipe outer wall $-580{ }^{\circ} \mathrm{C}$ [7].

In the analysis the value of heat flux density transferred to the diaphragm and the same temperature and heat flux density at deposit-diaphragm contacts were assumed. In the further part of the paper the analysis was carried out for a case of heating the steel pipe of the following dimensions: $r_{o}=0.025 \mathrm{~m}, r_{i}=0.017 \mathrm{~m}$, and for the heat conduction coefficient $\lambda_{P}=45 \mathrm{~W} / \mathrm{m} \mathrm{K}$. The calculations were carried out for the silicate 
boiler scale of the thickness of $t h_{d}=2.8 \mathrm{~mm}$ and the heat conduction coefficient $\lambda_{d}=0.3 \mathrm{~W} / \mathrm{m} \mathrm{K}$. The water temperature was $T_{f}=120^{\circ} \mathrm{C}$ and the heat transfer coefficient on the water's side was $\alpha_{f}=6000 \mathrm{~W} / \mathrm{m}^{2} \mathrm{~K}$. The heat flux on the pipe outer wall was $31 \mathrm{~kW} / \mathrm{m}^{2}$.

\section{Results of the analysis}

The accuracy in determination of the temperature distribution in the pipe with the boiler scale and in the boiler scale depends on the thermocouple location, $r^{*}$, precision of thermocouple location, $\Delta r^{*}$, thermocouple $\Delta T^{*}$ measurement accuracy and the accuracy in determination of the value of heat flux on the pipe outer surface.

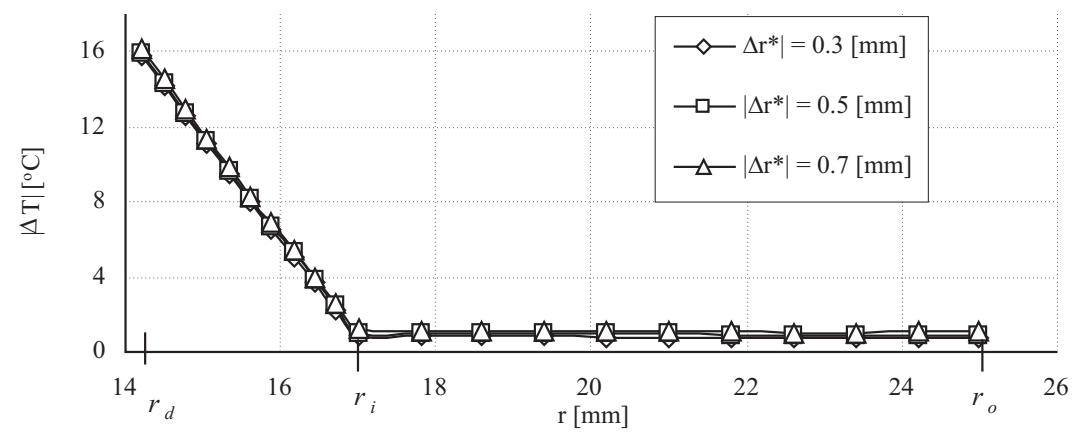

Figure 3: Influence of precision of thermocouple location on the accuracy of the solution of temperature distribution.

The analysis of how the precision of the thermocouple location influences the accuracy of temperature $\Delta T$ determination was performed. It was assumed that the thermocouple is located $2 \mathrm{~mm}$ under the surface of the pipe outer wall and the measurement is made with the accuracy $|\Delta T|=0.5{ }^{\circ} \mathrm{C}$. The analysis of the problem was carried out for the accuracy in determination of the heat flux on the outer wall $\left|\Delta \dot{q}_{o}\right|=1000 \mathrm{~W} / \mathrm{m}^{2}$. The analyzed deviations in the thermocouple location $\left|\Delta r^{*}\right|$ were $0.3,0.5$, and $0.7 \mathrm{~mm}$. Irrespective of $\Delta r^{*}$, temperature distributions $|\Delta T|$ were only slightly different, as shown in Fig. 3. This means that in the analyzed case the influence of precise placement of the thermocouple on the sensitivity of the solution is negligibly low. Of more importance on the temperature determination is the accuracy of temperature measurement made using the thermocouple. This dependence has been presented in Fig. 4 showing the 
sensitivity of the solution at the assumed $r^{*}=0.023 \mathrm{~m},|\Delta r *|=0.5 \mathrm{~mm}$ and $\left|\Delta \dot{q}_{o}\right|=1000 \mathrm{~W} / \mathrm{m}^{2}$. Distributions describing the relation between the thermocouple $\Delta T^{*}$ accuracy (from 0.3 to $0.7^{\circ} \mathrm{C}$ ) and the sensitivity of determination of the temperature distribution are parallel; and the differences correspond to the assumed thermocouple measurement accuracies. This results from the linear dependence between the sensitivity of temperature measurement made using the thermocouple $\Delta T^{*}$ and the accuracy of the function of temperature distribution in the pipe and in the boiler scale.
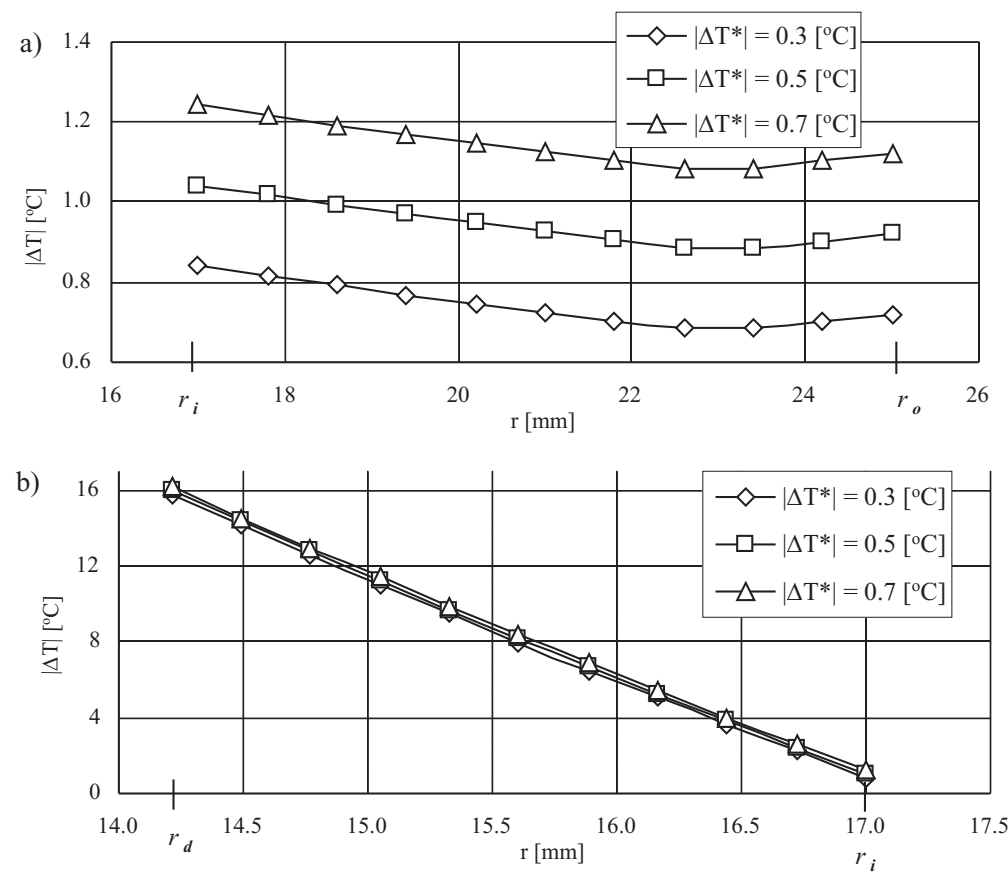

Figure 4: Influence of the thermocouple accuracy on the accuracy of the solution of temperature distribution a) in the diaphragm material b) in the deposit.

From the measurement point of view, determination of the heat transfer coefficient on the outer side is the most difficult. It determines the amount of transferred heat and has a significant influence on the accuracy of the obtained solutions. For $r^{*}=23 \mathrm{~mm},\left|\Delta T^{*}\right|=0.5^{\circ} \mathrm{C}$ and $\left|\Delta r^{*}\right|=0.5$ were assumed. When the distance from the pipe outer wall where the heat flux was determined increases, the error of temperature determination $|\Delta T|$ grows exponentially, as shown in Fig. 5, and for $\left|\Delta \dot{q}_{o}\right|=1500 \mathrm{~W} / \mathrm{m}^{2}$ on the boiler 
scale surface it reaches a temperature close to $25^{\circ} \mathrm{C}$. For the analyzed case the accuracy of the temperature determination on the wall of the boiler scale of the radius $r_{d}$ is one order of magnitude smaller than at the boiler scale-pipe contact point (Fig. 5). Hence, the error of the heat flux determination has a major influence on the accuracy of determination of the function of temperature distribution in the boiler scale.
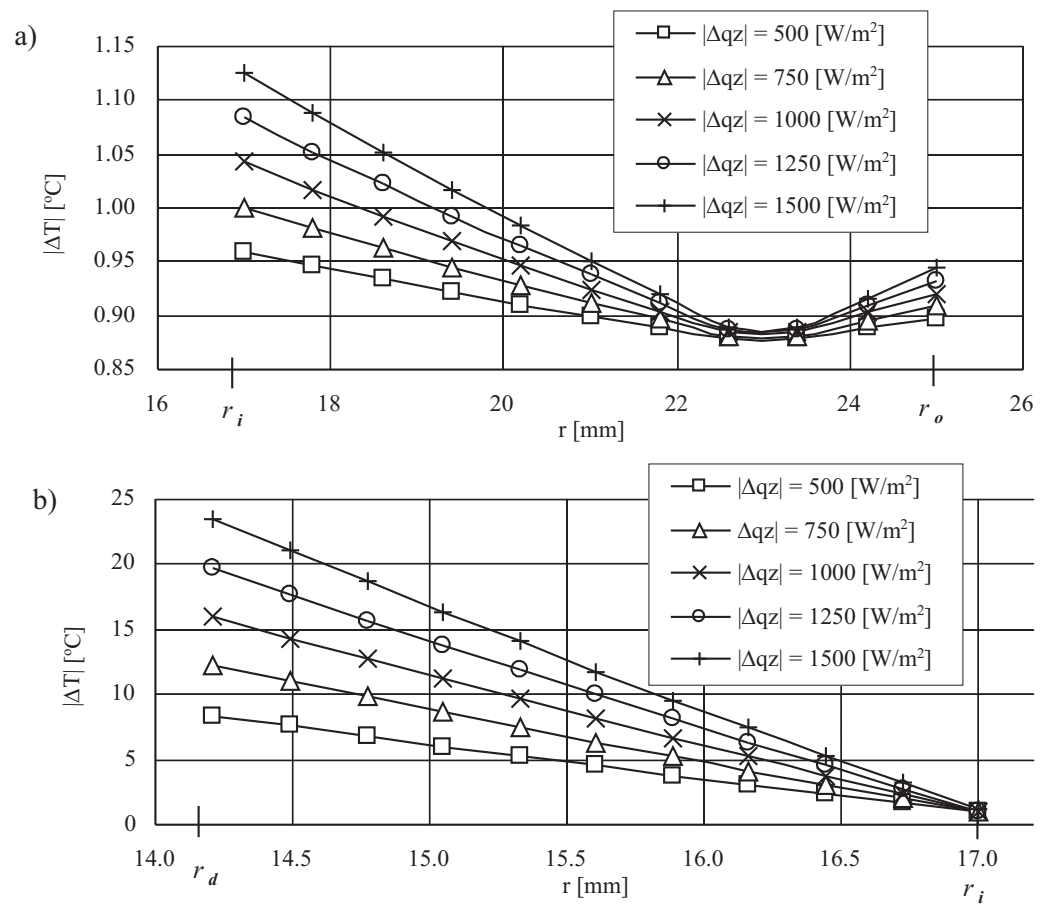

Figure 5: Influence of the accuracy in determination of the heat flux on the accuracy of the solution of temperature distribution: a) in the diaphragm material b) in the deposit.

The accuracy of temperature determination on the pipe outer wall subjected to the greatest thermal loads depends mainly on the location of thermocouple $r^{*}$, and thus, on the distance of the thermocouple from the pipe outer wall $\delta^{*}=r_{o}-r^{*}$. It is advantageous to place the thermocouple possibly close to the pipe outer wall to accurately determine the temperature on the outer wall of the pipe. This relation is shown in Fig. 6.

While making calculations, a simulation of temperature and heat flux distributions dependent on the scale deposit thickness was made. Measurement error of the heat flux on the outer wall of the tube, being the result of 


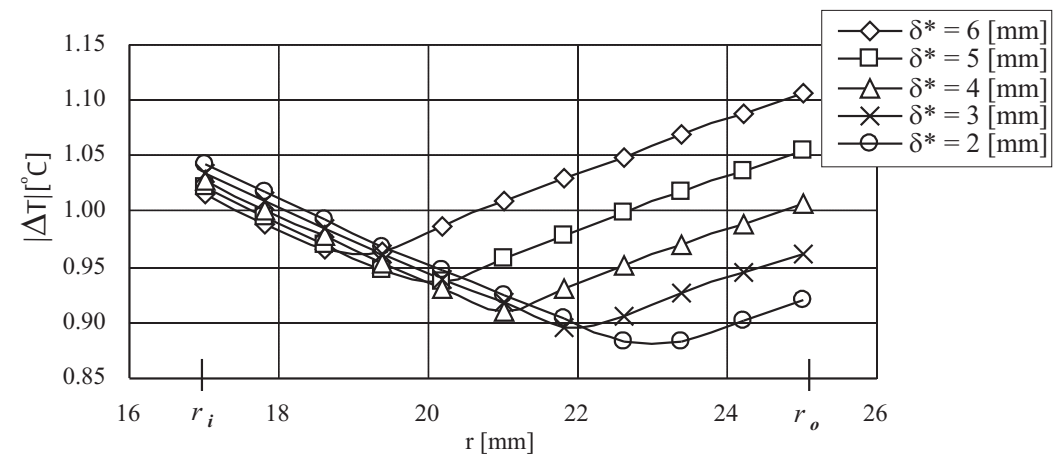

Figure 6: Influence of the thermocouple location on the accuracy of the solution of the temperature distribution.

a)

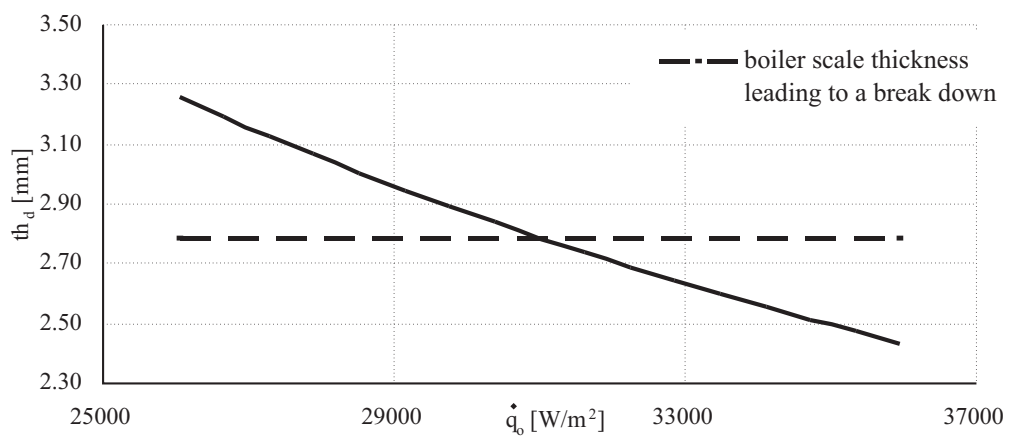

b)

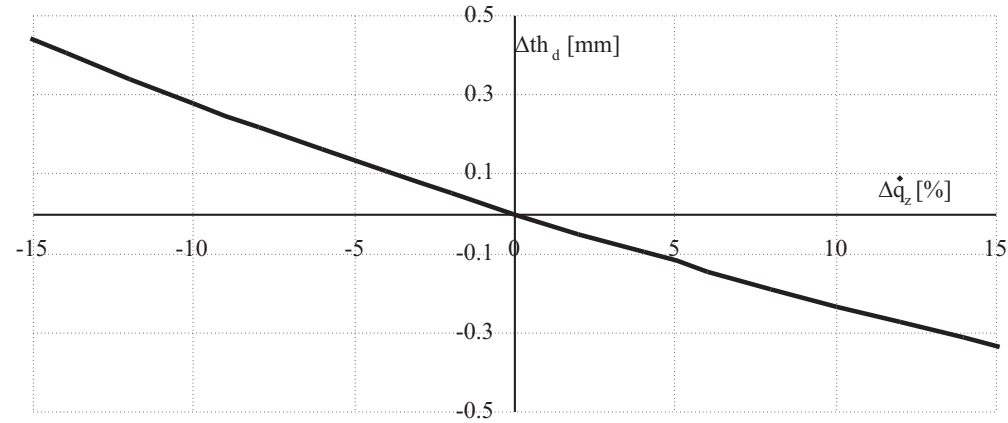

Figure 7: Influence of the heat flux density disturbance on the determined deposit thickness a) for the measurable values of the heat flux density b) for the relative values of the heat flux density.

low accuracy of the measurement method, was analysed. For the analysed value of the heat flux density (on the edge) equal to $\dot{q}_{o}=31 \mathrm{~kW} / \mathrm{m}^{2}$, the 
values of the silicate-based scale thickness $t_{h d}=2.8 \mathrm{~mm}$ and the difference in the obtained value of the deposit thickness $\Delta t h_{d}$ were calculated with the disturbance of the heat flux measurement equal to $\pm 15 \%$ (Fig. 7).

For the heat flux density of $35.65 \mathrm{~kW} / \mathrm{m}^{2}$, constituting $115 \%$ of the value, the deposit thickness equals to approx. $2.4 \mathrm{~mm}$ and it is $0.3 \mathrm{~mm}$ lower than the value at which the boiler should be shut down. An error in calculation $\dot{q}_{o}$ may lead to premature closing down the boiler for descaling, what results in economic losses. When the determined value $\dot{q}_{o}=31 \mathrm{~kW} / \mathrm{m} 2$, i.e. is $15 \%$ higher than it actually is $\left(26.35 \mathrm{~kW} / \mathrm{m}^{2}\right)$, the thickness of deposit equals to $3.2 \mathrm{~mm}$ and it is $0.4 \mathrm{~mm}$ higher than the calculated maximum deposit thickness not leading to the tube damage. The silicate-based scale thickness $g=3.2 \mathrm{~mm}$ is corresponded by the temperature of the outer wall $T_{o}$ above $600{ }^{\circ} \mathrm{C}$ which causes the diaphragm damage.

\section{Conclusions}

The paper presents the results of the analysis of temperature distributions in the wall of a heat exchanger tube with boiler scale precipitating from water on the pipe inner side. The analysis was performed for a heat flow through a steel pipe of the heat exchanger covered with three different types of boiler scale. Calculations were performed taking the following into account: inaccuracy in temperature measurement in the pipe material, inaccuracy in the thermocouple installation and for the variable heat flux transferred through the baffle. The first part of the paper was dedicated to determination of the thickness of the boiler scale through analysis of the inverse heat conduction problem. In the second one, the sensitivity of temperature distribution was analyzed depending on the obtained measurement accuracy. The accuracy of the solution of temperature distribution in the steel pipe of the heat exchanger covered with mineral deposits depends primarily on the precise determination of the heat flux on the pipe outer wall. The method requires a precise determination of this flux because any disturbance of the value may result in far too low estimation of the temperature value on the pipe outer surface, which leads to a damage of the heat exchanger pipes. 


\section{References}

[1] Björck A., Dahlquist G.: Numerical Methods. PWN, Warsaw 1983.

[2] Ciatkowski M.: Selected Methods and Algorithms for Solving the Inverse Problem of Heat Conduction Equation. Wydawnictwo Politechniki Poznańskiej, Poznań 1996.

[3] Duda P., Taler J.: A new method for identification of thermal boundary conditions in water-wall tubes of boiler furnances. Int. J. Heat Mass Tran. 52(2009) $1517-1524$.

[4] Helmut B., Joachim P.H.: Scales in evaporators. Int. Sugar J. 105(2003), 1258, $475-480$.

[5] Kleva S.: Boiler inspection, maintenance safety. HPAC Heating, Piping, Air Conditioning Eng. 81(2009), 4, 28-31.

[6] Kosma Z.: Numerical Methods for Engineering Applications. Radom UT, Radom 2007.

[7] Krajewska M., Cialkowski M., Bartoszewicz J.: The analysis of influence of boiler scale on the distribution of temperature in the pipe material. Thermodynamics in Science and Technology, Proc. 1-st Int. Congress on Thermodynamics Poznan, Poland 2011, 69-78.

[8] TAler D., SURY A.: Inverse heat transfer problem in digital temperature control in plate fin and tube heat exchangers. Arch. Thermodyn. 32(2011), 4, 17-31.

[9] Taler J., Duda P., Węglowski B., Zima W., Grądziel S., Sobota T., Taler D.: Identification of local heat flux to membrane water-walls in steam boilers. Fuel 88(2009), 305-311.

[10] Theodorou J.: How to prevent steam-boiler failure. HPAC Heating, Piping, AirConditioning Eng. 80(2008), 8, 34-39. 